\title{
Chapter 23 \\ The Role of Multi-Stakeholder Platforms for Creating an Enabling Climate Change Policy Environment in East Africa
}

\author{
Mariola Acosta, Edidah Lubega Ampaire, Perez Muchunguzi, \\ John Francis Okiror, Lucas Rutting, Caroline Mwongera, Jennifer Twyman, \\ Kelvin M. Shikuku, Leigh Ann Winowiecki, Peter Läderach, \\ Chris M. Mwungu, and Laurence Jassogne
}

\subsection{Introduction}

With climate change posing a rising threat to rural livelihoods in East Africa (Niang et al. 2014; Kahsay and Hansen 2016), the need for adaptation and mitigation strategies has gained increasing attention among policymakers (Liwenga et al. 2014). Although the region has made advances in building the relevant governance and policymaking systems, major challenges remain, including insufficient coordination between institutions and government levels; limited access of policymakers and

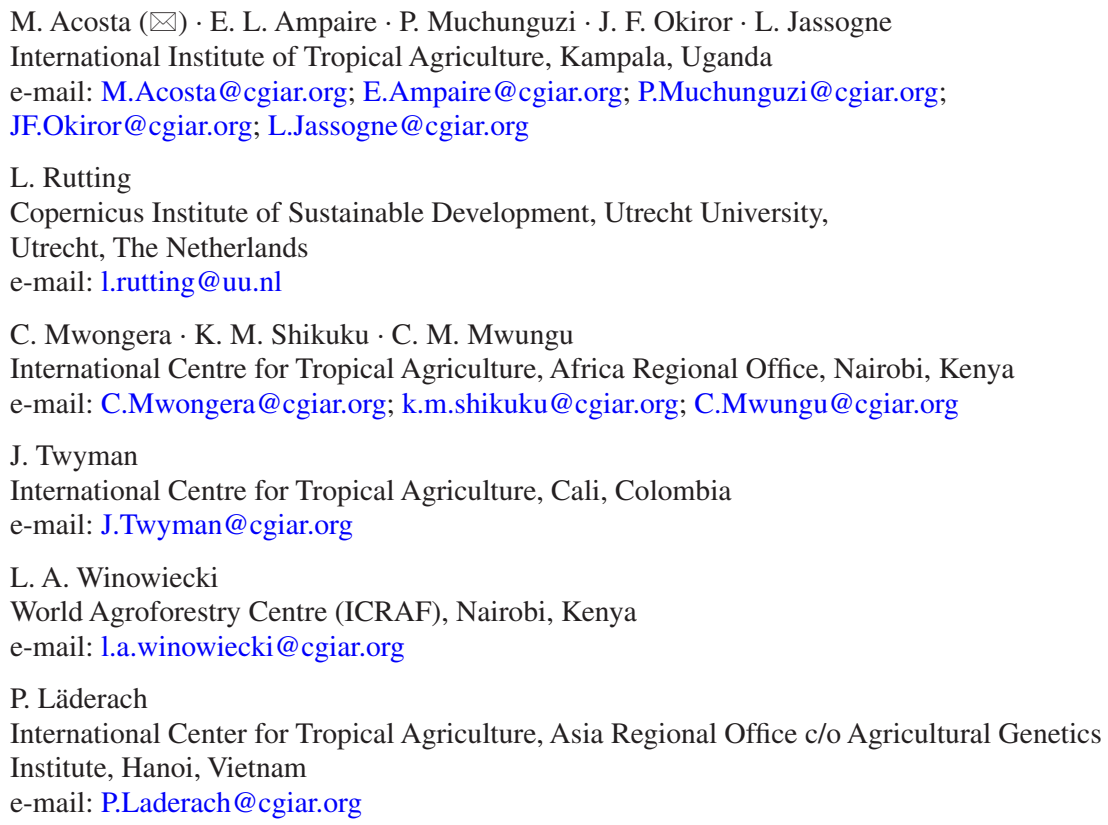


technical staff to empirical evidence; and insufficient funding (Minde et al. 2013; Asekenye et al. 2016; Ampaire et al. 2017).

Multi-stakeholder platforms (MSPs) bring together representatives from different interest groups to discuss shared challenges, opportunities, policy actions and advocacy strategies (Warner 2005). They have the potential to tackle complex development challenges and to assist in the scaling up of necessary innovations (Hermans et al. 2017). In the realm of agricultural development, MSPs have played a pivotal role in addressing many complex problems around the world (for a good overview and a selection of case studies see Dror et al. 2016). Recent studies also demonstrate MSPs' potential in addressing climate change (Pinkse and Kolk 2012).

With its three-part approach to climate change-mitigation, adaptation and food security - climate-smart agriculture (CSA) has been gaining increasing attention. While there has been considerable research on scaling up CSA practices, less attention has been given to assessing the policy environments most conducive to addressing climate change (Jordan and Huitema 2014). Such research is crucial, as the sustainable scaling up of CSA technologies can seldom be achieved without an enabling policy environment (Ampaire et al. 2015; Barnard et al. 2015).

The objective of this chapter is to examine the role of MSPs in facilitating climate change policymaking in East Africa through a case study of eight national and subnational MSPs in Uganda and Tanzania.

\subsection{Methods}

The Policy Action for Climate Change Adaptation (PACCA) project $^{1}$ (2014-2017) focused on building climate-resilient food systems in Uganda and Tanzania by coordinating policies and institutions at the local, regional and national levels. The empirical data for this chapter was collected through:

- Participant observation and meeting minutes: Between July 2014 and December 2017, principal members of the research team attended a total of 80 MSP meetings and events. Researchers took notes, made observations and reviewed meeting minutes.

- Questionnaires: Researchers administered a baseline questionnaire at the inception meetings of the national platforms to assess participants' knowledge, attitudes and skills regarding three main topics: (i) impacts of climate-change adaptation, (ii) available, locally appropriate adaptation options and (iii) policy formulation and implementation processes. Information was collected from 29 stakeholders in Tanzania (31\% women, 69\% men) and 39 in Uganda (38\% women, $62 \%$ men).

\footnotetext{
${ }^{1}$ Initiative of the CGIAR Research Program on Climate Change, Agriculture and Food Security (CCAFS).
} 
- Social network analysis (SNA) was conducted to collect information on the key organizations for knowledge exchange. Data were collected from participants using a multistep process during the launch of district platforms in Nwoya ( $n=24)$ and Mbale $(n=21)$ in December 2015 and June 2016, respectively. Participants were first asked to list all the institutions they represented, then all the organizations with which they collaborated. Finally, from these lists of organizations, participants identified which they considered the most important for knowledge exchange. Analysis of the data was undertaken using Gephi 0.9.1 software.

\subsection{Results and Discussion}

\subsubsection{Establishment and Operation of the MSPs}

The climate change MSPs were established between 2014 and 2015. In Tanzania three were formed, one national and two subnational (in Lushoto and Kilolo districts). In Uganda five were established, one national and four subnational (in Nwoya, Rakai, Luwero and Mbale districts). The subnational platforms influenced district-level policymaking and informed the national platforms, which in turn influenced national policymaking through information-sharing with parliamentarians and national ministries. Having both subnational and national organizations facilitated a bidirectional flow of information. This integrated approach is important because, although the effects of climate change are felt locally and technologies must be context-specific, change happens most effectively within an enabling national policy environment.

While PACCA acted as the initiator of the platforms, funded some of their activities and remained a stakeholder member, the MSPs functioned largely as independent entities. The national platform in Uganda was hosted by the Climate Change Department of the Ministry of Water and Environment, and the one in Tanzania by the Environmental Management Unit of the Ministry of Agriculture Livestock and Fisheries (MALF-EMU). In the districts, the platforms were hosted by the national offices of environment and natural resources. Embedding the platforms within government structures provided those official bodies with convening power, a greater sense of ownership over the process and, ultimately, offered the platforms a pathway to sustainability. Facilitation of meetings was entrusted to members of the platform-hosting institutions who were recognized for their authority, their central role in local knowledge exchange and their credibility among other stakeholders.

Participant observation and an examination of minute meetings revealed that the platforms enabled their participants to share experiences and research findings on climate change. The PACCA project, as a member of the MSPs, contributed to the generation and dissemination of research findings on CSA and climate change adaptation (specifically on-farm trade-off and synergies for CSA, drivers for 
adoption of CSA, prioritization among CSA options for greater impact, scenarioguided policy development, policy-actor networks and gender-responsive policymaking), thereby contributing to an enhanced science-policy interface. This sharing of research evidence and experience became the basis for discussions and helped define the efforts by the MSPs to influence policy. Platform meetings, which generally took place quarterly, had two main sessions: the first featured sharing of research knowledge and experience, while in the second decisions were made in plenary through inclusive participatory processes, which normally involved working in groups followed by a plenary discussion. These processes of knowledge sharing contributed towards building trust between stakeholders and facilitated finding common goals and interests, which helped foster unified action.

\subsubsection{The Role of MSPs in Promoting CSA}

\subsubsection{Knowledge Creation and Capacity Building}

Initial knowledge levels about climate change and CSA varied widely among participants. The questionnaire revealed that stakeholders were generally familiar with the impacts of climate change, with $83 \%$ in Tanzania $(n=29)$ and $71 \%$ in Uganda $(n=39)$ reporting a high level of understanding. Knowledge of locally appropriate adaptation options was considerably lower, with 58\% in Tanzania and $77 \%$ in Uganda reporting low or medium knowledge levels. Knowledge of policy processes was higher in Tanzania, where $41 \%$ and $45 \%$ rated their level of familiarity as high in policy formulation and implementation processes, respectively, as compared to $21 \%$ and $29 \%$ in Uganda. These differences can be explained by the actor composition of MSPs: Uganda had a higher proportion of representatives from non-state actors in their MSPs, whereas MSPs in Tanzania were disproportionately composed of government representatives who were familiar with policy formulation and implementation processes (Table 23.1).

Table 23.1 Composition of national MSPs at inception meetings (OctoberNovember 2014)

\begin{tabular}{l|l|l}
\hline \multirow{2}{*}{ Institution category } & \multicolumn{2}{|l}{ Sample size } \\
\cline { 2 - 3 } & Uganda & Tanzania \\
\hline Association & 5 & - \\
\hline Academia & - & 3 \\
\hline Consultant & - & 1 \\
\hline Media & 2 & - \\
\hline NGOs/CSOs & 22 & 3 \\
\hline Government ministries & 2 & 8 \\
\hline Government departments & 1 & 6 \\
\hline Government agencies & 2 & 5 \\
\hline Local government & 4 & 2 \\
\hline Research & 1 & 1 \\
\hline Total & $\mathbf{3 9}$ & $\mathbf{2 9}$ \\
\hline
\end{tabular}


Once the results of the questionnaires were presented to the MSPs, they made changes to their meeting structures in order to address the knowledge gap: all actors were invited to share their experiences with climate change adaptation projects, and experts regularly presented research-based evidence on the CSA technologies favorable for each region. This transfer of knowledge was expected to enhance the technical capacity of the platforms' members, which in turn was expected to translate into attitudinal and behavioral change both within each member's organization and in the actions of the platforms as a whole.

While an end-line study was not available at the time this chapter was written, limiting our ability to quantify the extent of participants' learning over time, there is evidence of the platforms' impact. In event evaluation forms, participants indicated that they shared their newly acquired knowledge with colleagues, politicians and community members. The role of the MSPs in the dissemination of knowledge was also publicly acknowledged by a representative of the Climate Change Department in Uganda, who stated that the MSPs "have improved the understanding of climate change and its impacts, thus enabling public institutions, individuals and non-state actors to tap into the opportunities and co-benefits arising from mitigation and adaptation actions" (Semambo 2017).

Results of the SNA showed that institutions in both districts were linked through information-sharing processes, but the relationships were not necessarily reciprocal. For example, in Nwoya the most important participants for knowledge exchange were the District Local Government and ZOA, a Dutch NGO, but there was no exchange between the two. We found a similar situation in Mbale (Fig. 23.1), where the organizations considered important for knowledge exchange were Mbale District Local Government (MDLG), National Forestry Authority (NFA) and

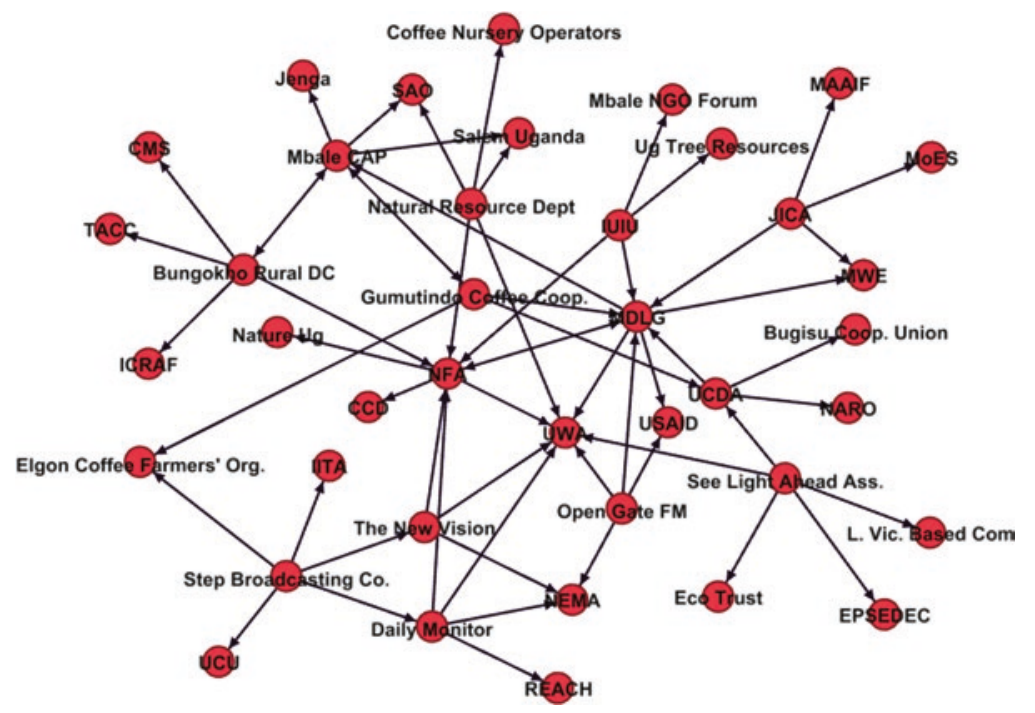

Fig. 23.1 Knowledge exchange sociogram for Mbale District 
Uganda Wildlife Authority (UWA), but the knowledge exchange relationship existed only between NFA and MDLG, not with UWA. The SNA also identified institutions that acted as bridges for other institutions that would otherwise not be connected to the knowledge network (e.g., Bungokho Rural DC). In both MSPs, the district local governments were among the institutions better connected in terms of knowledge sharing. This further justifies the strategy of hosting the district MSPs within the local governments as a way to promote sustainability, knowledge exchange and coordination of local climate-change actors.

\subsubsection{Influencing Subnational and National Policies}

The platforms' meetings played a role in promoting collective action to influence national and subnational policies. In both Uganda and Tanzania, the platforms' actions were decided in plenary on the basis of the research-based evidence on CSA, responsive and equitable policymaking and climate change adaptation. MSPs were able to contribute and influence key national policies. In Uganda the Climate Change MSP was recognized as having influenced and complemented a number of policy reviews and strategic development plans (Semambo 2017). In both Uganda and Tanzania the national platforms were also active in influencing national climate change policy (Table 23.2).

Like the national platforms, the district platforms had regular meetings that involved the sharing of experiences with context-specific adaptation strategies and locally appropriate CSA options. Key representatives of the district platforms were also members of the national platforms, ensuring coordinated action. District platforms engaged in participatory zonal planning of their territories for the prioritization of adaptation investments - an example of the type of initiatives aimed at fostering a conducive policy environment for the scaling up of CSA practices which MSPs are especially well suited to address precisely because they require the collaboration of stakeholders from different sectors and across different scales. Stakeholders began by defining the zoning criteria and dividing the area into different zones based on what they perceived as locally important factors: the main source of livelihood and farming system (Rakai), altitude (Kilolo), rainfall gradient (Luwero) or a combination of these (Lushoto). The fact that districts differed in the zoning criteria they employed and the number of zones they identified highlights the fact that adaptation needs and local priorities are unique to each territory. The zoning was usually followed by stakeholder discussions on each of the zone's main enterprises, the effects of climate change on these enterprises, and the pertinent policy issues and adaptation measures needed to overcome these constraints.

In subsequent meetings, district officers and representatives of the platforms would prioritize the issues to be integrated in the district development plans. Since the formation of the platforms, there has been progress in incorporating CSA components in the District Development Plans in Uganda and in the District Agriculture Development Plans in Tanzania. For example, in Lushoto, Tanzania, 
Table 23.2 Policy engagement activities of the national climate-change MSPs

\begin{tabular}{|c|c|}
\hline $\begin{array}{l}\text { Uganda national MSP } \\
\text { activities }\end{array}$ & Tanzania national MSP activities \\
\hline $\begin{array}{l}\text { Scenario-guided policy review } \\
\text { of the Uganda National } \\
\text { Agricultural Sector Strategic } \\
\text { Plan (ASSP) }\end{array}$ & $\begin{array}{l}\text { Water-use technology study used in a policy engagement } \\
\text { meeting with the National Irrigation Commission, Basin Water } \\
\text { Boards and the Ministry of Agriculture, Food Security and } \\
\text { Cooperatives. Recommendations given on the need to promote } \\
\text { efficient water-use technologies and other CSA practices as a } \\
\text { package, rather than individual technologies, for enhanced } \\
\text { adoption of these technologies at large scale }\end{array}$ \\
\hline $\begin{array}{l}\text { Preparatory meetings to } \\
\text { organize and ensure a } \\
\text { coordinated approach of the } \\
\text { Uganda position in the COP } 21\end{array}$ & $\begin{array}{l}\text { Scenario-guided policy review of the National Environmental } \\
\text { Policy }\end{array}$ \\
\hline $\begin{array}{l}\text { Participation in the Joint } \\
\text { Sector Reviews of the } \\
\text { Ministry of Water and } \\
\text { Environment (MWE) and the } \\
\text { Ministry of Agriculture, } \\
\text { Animal Industry and Fisheries } \\
\text { (MAAIF) }\end{array}$ & $\begin{array}{l}\text { Informing the development of the Intended Nationally } \\
\text { Determined Contributions (INDCs) }\end{array}$ \\
\hline $\begin{array}{l}\text { Informing the draft irrigation } \\
\text { policy }\end{array}$ & \multirow[t]{3}{*}{$\begin{array}{l}\text { Participation in the development of the CSA Country Plan for } \\
\text { Tanzania }\end{array}$} \\
\hline $\begin{array}{l}\text { Participation in a live national } \\
\text { dialogue on climate change } \\
\text { and women }\end{array}$ & \\
\hline $\begin{array}{l}\text { Participation in several } \\
\text { climate-change workshops } \\
\text { organized by other actors }\end{array}$ & \\
\hline
\end{tabular}

the district council allocated the equivalent of US\$3800 to execute various CSA interventions for the financial year 2016-2017. In Luwero, Uganda, district officials prioritized working on the institutional framework for addressing climate change in the district, and in Rakai, Uganda, a District Climate Change Action Plan was created.

Conscious of the importance of using scientific evidence on gender, CSA and climate change to influence legislative decisions, the MSPs in Uganda undertook a National Reflection Workshop with members from civil society organizations, research institutions, local governments, ministries and the media. The evidence and messages that emerged from the event, together with information from the continued policy engagement that followed, were presented at a high-level event attended by members of the Uganda Parliamentary Forum on Climate Change and the Parliamentary Forum on Food Security, Population and Development. The event helped raise awareness and advocate for gender responsiveness in climate change adaptation among members of Parliament amidst discussions on the Uganda Climate Change Bill, the Biotechnology Bill and the pre-negotiations for the COP22 in Morocco. Inspired by the event in Uganda, the LA in Tanzania organized 
a sister event in 2017 with members of the Tanzanian Parliament, where evidence was presented to encourage legislators to ensure gender-responsive climate change policymaking. In addition to these parliamentarian engagements, representatives of the MSPs have also participated in other high-level policy engagements organized by partner organizations.

With growing evidence of their efficacy and acceptance by stakeholders, the MSPs have become increasingly institutionalized. In Uganda the national Climate Change Department is establishing a climate change MSP at the ministry, department and agency levels - independently of the PACCA project - to operationalize article 6 of the United Nation Framework Convention on Climate Change (UNFCCC) on capacity building. In Tanzania, the district government of Lushoto has formalized the incorporation of the MSPs into their district frame and has replicated the MSP model in villages, appointing "ambassadors" who monitor and report on their respective activities. Furthermore, officials from MALF-EMU have expressed interest in using the MSP model and acknowledged MSPs as central to national climate-change policy planning and to the scaling up of CSA in the country (Okiror and Cramer 2017). Further research will be needed to assess the levels of funding provided to these MSPs and what affects the availability of funds has on their operation, efficacy and perceived legitimacy.

\subsection{Implications for Development}

Through a case study in Uganda and Tanzania, this chapter has examined the role of MSPs in influencing climate change policy processes. MSPS foster the sharing of information among diverse stakeholders and allow participatory approaches for influencing policy recommendations across multiple governance levels. We argue that these MSP interventions can help build an enabling policy environment for climate - change adaptation and mitigation policy, as evidenced by the scenarioguided policy planning processes, CSA participatory zonal planning exercises and multiple policy reviews and consultations. With specific reference to the role of MSPs in fostering CSA science-policy dialogue, the results of the questionnaire highlighted the need for greater knowledge-sharing among stakeholders. Findings from the social network analysis suggest the importance of platform composition in the knowledge-exchange process. Furthermore, concrete policy action such as budgeting for tangible CSA projects at the local level (e.g., Lushoto, district MSPs), recommending specific packages of CSA water-efficient technologies for enhanced adoption (Tanzania, national MSPs) and mainstreaming CSA and climate change in district development plans (Uganda, Tanzania district MSPs) exemplifies the role that continuous science-policy interaction through MSPs can have in influencing policymaking.

While these MSP processes have succeeded in enhancing CSA science-policy dialogues and promoting evidence-based policy outcomes in East Africa, addi- 
tional research is needed if the MSP model is to be successfully replicated elsewhere. Specifically, further context-specific studies are needed on the optimal balance between non-state actors (including the private sector) and government representatives in the platforms, as these case studies appear to suggest that an overrepresentation of either could hinder the ability to achieve policy change. End-line evaluation and follow-up studies will also be required to determine whether the degree and manner of the East African MSPs' embeddedness in local government structures was sufficient to maintain their financial sustainability over time while preserving their independence and participatory approach.

\section{References}

Ampaire EL, Providence H, Van Asten P, Radeny M (2015) The role of policy in facilitating adoption of climate-smart agriculture in Uganda. CGIAR Program on Climate Change, Agriculture and Food Security (CCAFS), Copenhagen

Ampaire EL, Jassogne L, Providence H et al (2017) Institutional challenges to climate change adaptation: a case study on policy action gaps in Uganda. Environ Sci Pol 75:81-90. https:// doi.org/10.1016/j.envsci.2017.05.013

Asekenye C, Ampaire E, Epp MV, Van Asten P (2016) Climate Change Social Learning (CCSL) report for Uganda and Tanzania. Influencing and linking policies and institutions from national to local level for the development and adoption of climate-resilient food systems. International Institute of Tropical Agriculture (IITA), Kampala

Barnard J, Manyire H, Tambi E, Bangali S (2015) Barriers to scaling up/out climate smart agriculture and strategies to enhance adoption in Africa. Forum for Agricultural Research in Africa, Accra

Dror I, Cadilhon J-J, Schut M et al (eds) (2016) Innovation platforms for agricultural development: evaluating the mature innovation platforms landscape. Routledge, London

Hermans F, Sartas M, van Schagen B et al (2017) Social network analysis of multi-stakeholder platforms in agricultural research for development: opportunities and constraints for innovation and scaling. PLoS One 12:e0169634. https://doi.org/10.1371/journal.pone.0169634

Jordan A, Huitema D (2014) Policy innovation in a changing climate: sources, patterns and effects. Glob Environ Chang 29:387-394. https://doi.org/10.1016/j.gloenvcha.2014.09.005

Kahsay GA, Hansen LG (2016) The effect of climate change and adaptation policy on agricultural production in eastern Africa. Ecol Econ 121:54-64. https://doi.org/10.1016/j. ecolecon.2015.11.016

Liwenga ET, Jalloh A, Mogaka H (2014) Review of research and policies for climate change adaptation in the agriculture sector in East Africa. Future Agricultures Consortium, Brighton

Minde H, Kateka A, Tilley H, et al (2013) Tanzania national climate change finance analysis. Overseas Development Institute, London/The Centre for Climate Change Studies, University of Dar es Salaam, London

Niang I, Ruppel OC, Abdrabo MA et al (2014) Africa. In: Barros VR, Field CB, Dokken DJ et al (eds) Climate change 2014: impacts, adaptation, and vulnerability. Part B: regional aspects. Contribution of working group II to the fifth assessment report of the intergovernmental panel on climate change. Cambridge University Press, Cambridge, UK, pp 1199-1265

Okiror JF, Cramer L (2017) Lessons for successful scaling of climate-smart agriculture innovations. https://ccafs.cgiar.org/blog/lessons-successful-scaling-climate-smart-agriculture-innovations. Accessed 22 Dec 2017 
Pinkse J, Kolk A (2012) Addressing the climate change—sustainable development nexus: the role of multistakeholder partnerships. Bus Soc 51:176-210

Semambo M (2017) PACCA project experience sharing. Ministry of Water and Environment (MWE). Climate Change Department. Kampala (Uganda)

Warner J (2005) Multi-stakeholder platforms: integrating society in water resource management? Ambient Soc 8:4-28

Open Access This chapter is licensed under the terms of the Creative Commons Attribution 4.0 International License (http://creativecommons.org/licenses/by/4.0/), which permits use, sharing, adaptation, distribution and reproduction in any medium or format, as long as you give appropriate credit to the original author(s) and the source, provide a link to the Creative Commons license and indicate if changes were made.

The images or other third party material in this chapter are included in the chapter's Creative Commons license, unless indicated otherwise in a credit line to the material. If material is not included in the chapter's Creative Commons license and your intended use is not permitted by statutory regulation or exceeds the permitted use, you will need to obtain permission directly from the copyright holder.

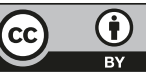

